\title{
Rational Finance, "Caput Mundi" Money: A Global Deception
}

\section{Fabrizio Pezzani*}

Department of Policy Analysis and Public Management, Bocconi University, Milan, Italy

\begin{abstract}
Today we study finance instead of economics and the Nobel Prize that the Swedish Academy invented for the latter in 1969, funded by its national bank, laid out the "red carpet" to replace economics with finance that is instead a derivative thereof. We have eradicated the principle of long term economics and 500 years of accountancy with shorttime liquidity. Rational finance and "caput mundi money" was created with absent and even illegitimate logical and scientific foundations. We here attempt to reconstruct the process underlying this "global deception".
\end{abstract}

Keywords: Rational finance; Caput mundi; Global deception; Money

\section{Introduction}

Financial equilibrium depends on economic equilibrium and not vice versa. Money has no value in itself but should represent a real asset that guarantees its value. As soon as this link ceased to exist, the value of the dollar-currency was no longer objective as conceived at Bretton Woods - 35 dollars per ounce of gold. The United States under pressure from internal and external problems found itself without gold and an untold and unrestrained monetary supply with a risk of its devaluation and collapse. For this reason, in 1971 Nixon unilaterally declared the discontinuation of the convertibility of the dollar into gold, switching abruptly from a fixed exchange rate system to a floating exchange rate system and thereby throwing the world into chaos. The invention of the petrodollar was functional to creating demand for dollars printed in excess and without limit, but would condemn us to a surge of inflation and the unprecedented explosion of public debt. This decision opened the world of geopolitics to a new kind of war made with finance. US Secretary of the Treasury John Connally openly stated, "The dollar is our currency but your problem". Here in Italy, we experienced a surge in inflation that brought us to our knees, totally unprepared for the financial attack of our first ally. The US hegemonic culture formed and was consolidated, turning their democracy into a narrow oligarchy increasingly detached from the reality of a world that is today radically changing the balance of power. The following graphs show the end of the real economy, American public debt growth and the inflationary spiral that swelled our debt (Figure 1).

The transition from gold to the dollar exchange standard led us from a flexible to a floating exchange rate system at the mercy of a growing monetary and then financial mass with new electronic payment methods that slowly suffocated the real economy. Subsequently, financial cycles lengthened and became increasingly deeper, as this graphs show (Figure 2).

Indeed, all the curves that in the post-war period indicated social and economic improvements, in exactly the same period in which we were plunged into infinite money (1970-75), the curves inverted and everything worsened, including US share capital and global inequality; history turned the page (Figure 3 ).

In the absence of real constraints, money assumed an infinite dimension and finance espoused this infinity, which is exactly and logically the opposite of a finite reality. Science allegedly affirmed that infinity, which in itself does not have a unit of measure, can be used to measure the real world that is instead finite and measurable. Aristotle's principle of non-contradiction states "A" cannot simultaneously occupy the position of "not-A" but is invalidated by contradicting the principles of logic and manipulating the facts. This ushered the era of infinite money with a dominant role based neither on scientific grounds nor on simple logic. The material finite became prey and hostage of the immaterial infinite and everything turned into a play of light and shadow as in the Chinese theatre where something is seen and constantly eludes.

When the printable volume of money became unlimited and uncontrollable, monetarism acquired an unnatural role because it raised infinite money above the finite, illogically determining its value and detached from reality. The trends of the financial prices of real assets were determined and influenced by endless speculation with exchanges that never closed, generating infinite financial volumes that nobody controlled. The prices of real assets and currencies were no longer based on real quantities but on endless bets as the oil and grain markets show (Figures 4-7).

Behind these volumes there is often nothingness but this generated the desired expectations to manoeuvre and guide markets that would magically become rational and exact. Expectations are not certain (rational) knowledge and thus reality becomes very different from what it would be if it were based on certain knowledge. The infinite deregulated monetary and financial mass was no longer controlled by the controllers who ended up colluding with the controlled. The economics that the great thinkers of the past studied, who took care of man and his central role in the economy, became a financial corollary that held it hostage and with endless paper money determined the real finite value according to propriety.

\section{The Era of Finance}

After the fall of the Berlin wall, the model was elevated to dogma and without losing time, the Academy of Sciences the following year ushered in "the time of finance", awarding the Nobel prize to Harry Markowitz, Merton Miller and William Sharpe for pioneering work in this field. In 1994, Robert Lucas came into play, winning the Nobel Prize and arguing that markets are rational and their rationality allows the best allocation of resources even if today we daily witness the opposite.

*Corresponding author: Fabrizio Pezzani, Department of Policy Analysis and Public Management, Bocconi University, Milan, Italy, Tel: 39-025836-3045; E-mail: fabrizio.pezzani@unibocconi.it

Received June 13, 2016; Accepted July 02, 2016; Published July 12, 2016

Citation: Pezzani F (2016) Rational Finance, "Caput Mundi" Money: A Global Deception. Bus Eco J 7: 223. doi:10.4172/2151-6219.1000223

Copyright: $\odot 2016$ Pezzani F. This is an open-access article distributed under the terms of the Creative Commons Attribution License, which permits unrestricted use, distribution, and reproduction in any medium, provided the original author and source are credited. 

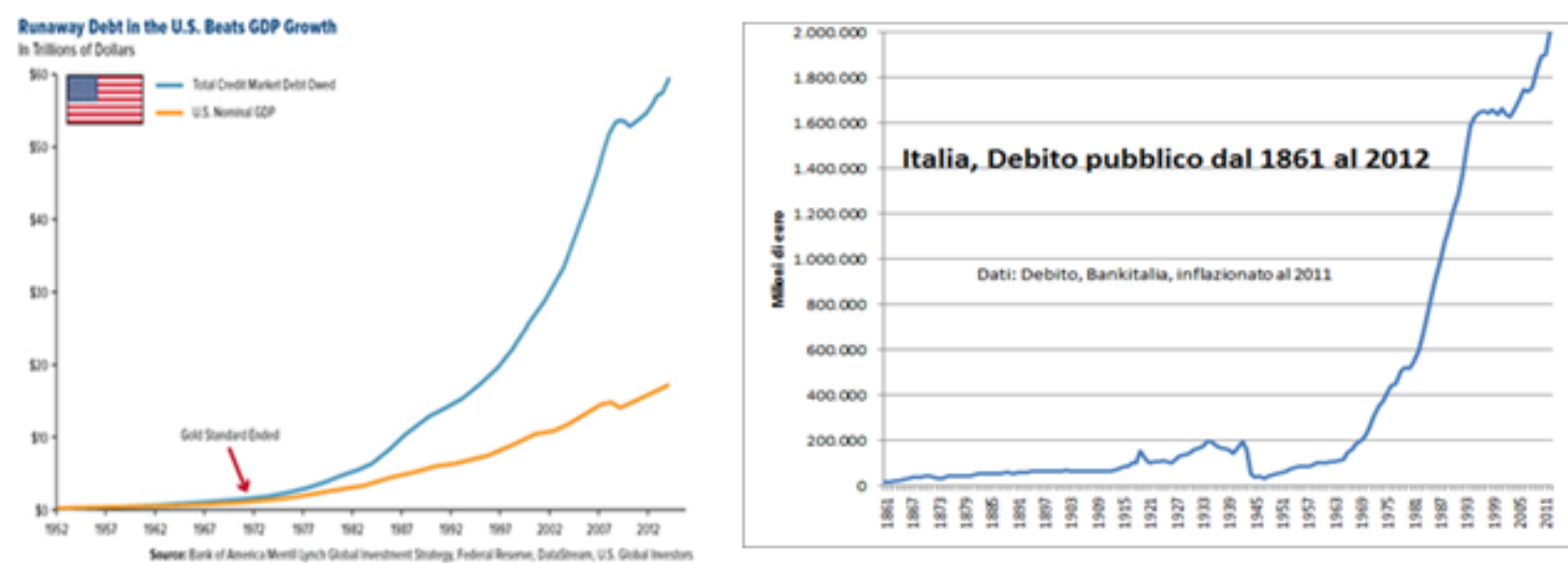

Figure 1: the end of the real economy, American public debt growth and the inflationary spiral that swelled our debt.

Financial cycles and crises are becoming longer and deeper

Financial and business cycles in the US

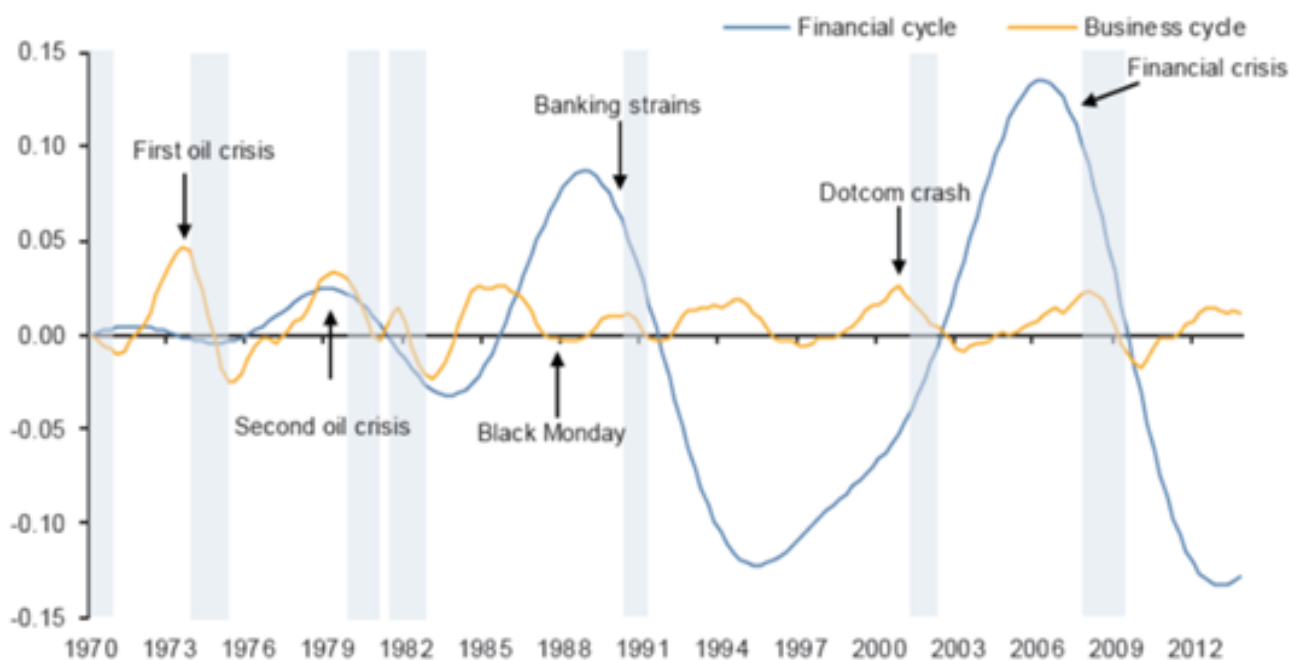

Figure 2: Financial and business cycles in the US.
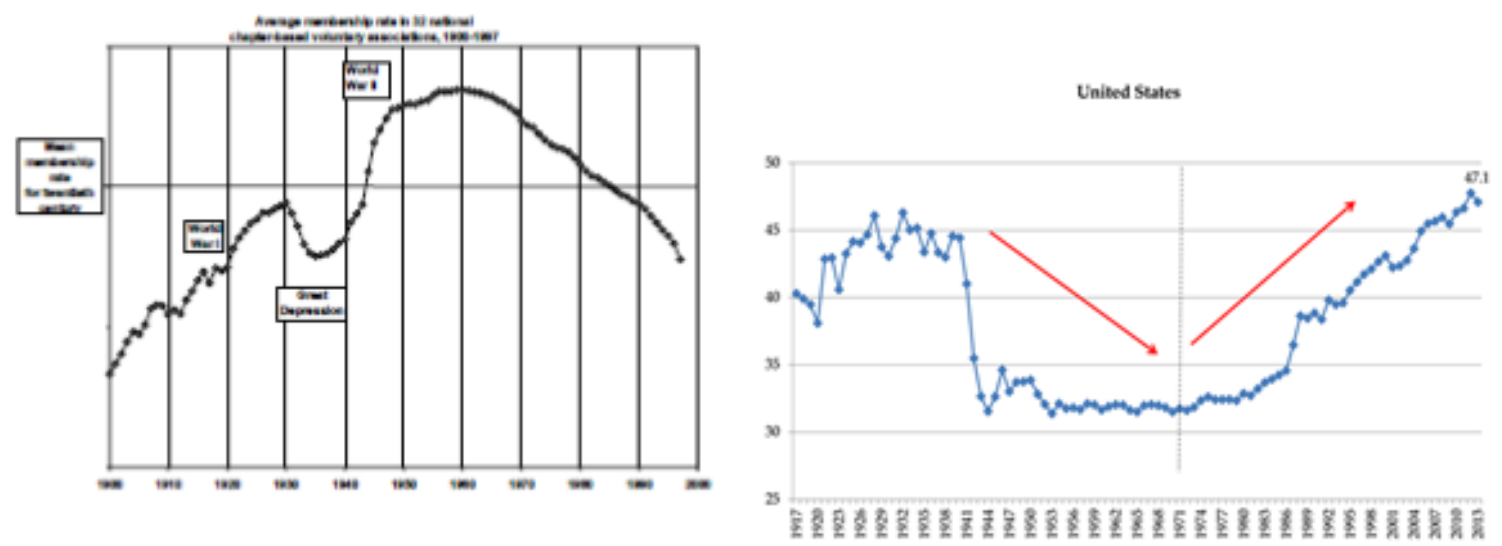

Figure 3: US share capital and global inequality. 


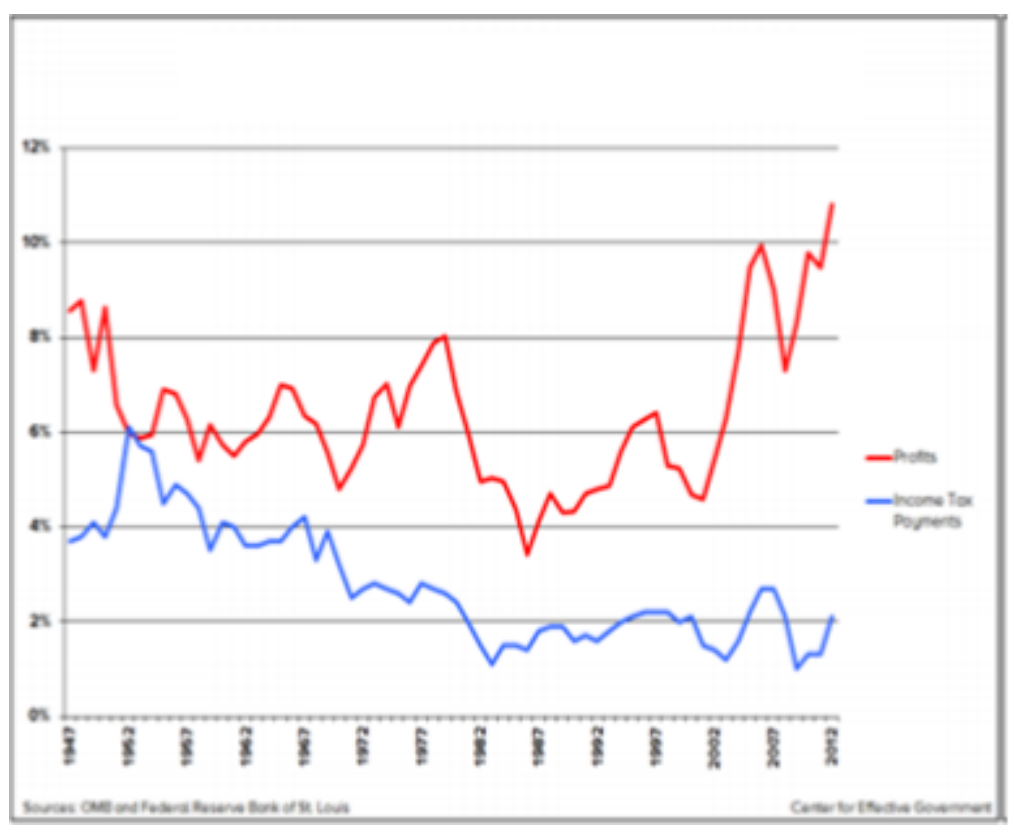

Figure 4: Corporate profits and income taxes paid as petcent of GDP.

\section{Real Household Income at Selected Percentiles:} 1967 to 2011

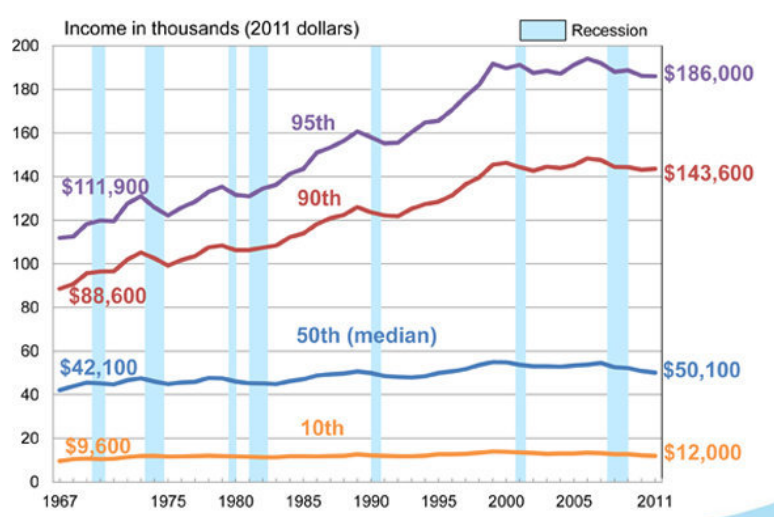

Figure 5: Real Hopsehold income at selected percentiles.

The Nobel Prize to Lucas is perhaps one of the most obvious devastating and logical contradictions that contributed to determining the financial chaos as incontrovertible truth. Stating that markets are rational and never wrong in allocating wealth because with the same information operators decide the same way implies some obvious and logical contradictions. The first concerns the denial of free will (all decide the same way) as if the socio-cultural context in which people operate cannot determine the choices and the priority of needs. Denial of free will is denying the person who then becomes a thing and democracy itself on which the social system should be based is then the opposite. The second concerns the alleged hypothesis of symmetry, a primary condition for the opportunity to decide based on "equal information". Lucas stated in substance that perfect competition is the priority condition for rational markets, unfortunately perfect competition does not exist and already we find ourselves in the sphere of the impossible. Sufficient here is observing the derivatives market where

\section{Inequality in Selected Countries}

Income share of the top 1 percent of earners

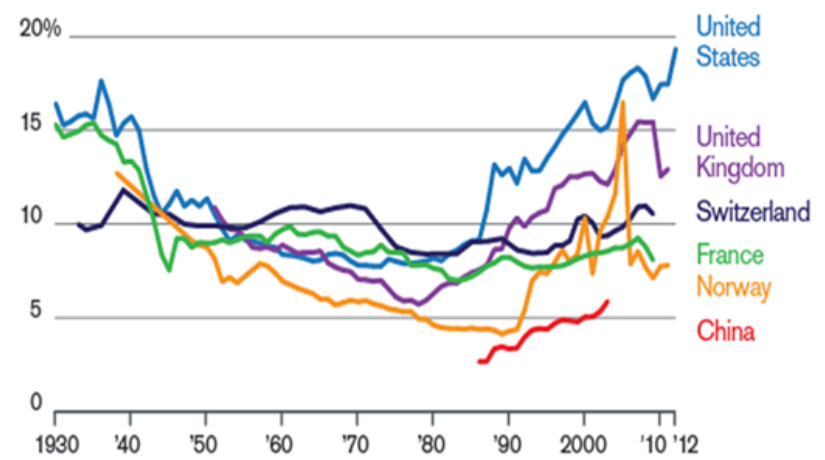

Figure 6: Inequality in selected countries.

$90 \%$ of transactions are made through only a few investment banks, clearly creating information asymmetry, and this concentration is far from perfect competition but functional to altering and manipulating "rational" expectations. In confirmation of this, some Wall Street investment banks were sentenced by the US Justice Department for the "fraudulent manipulation" of data that led to the sub-prime crisis. This is also a logical paradox that would make the great Aristotle turn in his grave. Indeed, if the cultural model to be pursued is maximising personal wealth, it is quite obvious that the dissemination of information that can increase the competitiveness of other subjects must logically be excluded because the end is asymmetrical to the means. In September 2007 - a year before the sub-prime crisis - Lucas again stated, "I am sceptical about the argument that the subprime mortgage problem will contaminate the whole mortgage market, that housing construction will come to a halt, and that the economy will slip into a recession". Arrogance not ignorance is the real limit to knowledge. 

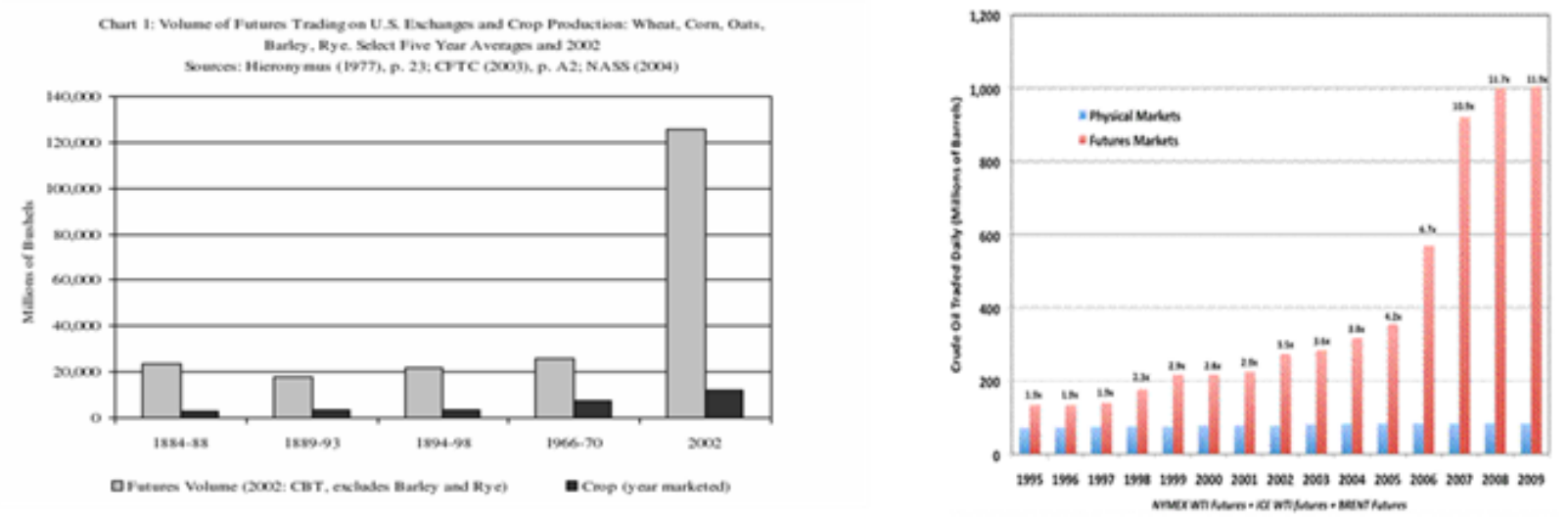

Figure 7: The prices of real assets and currencies.

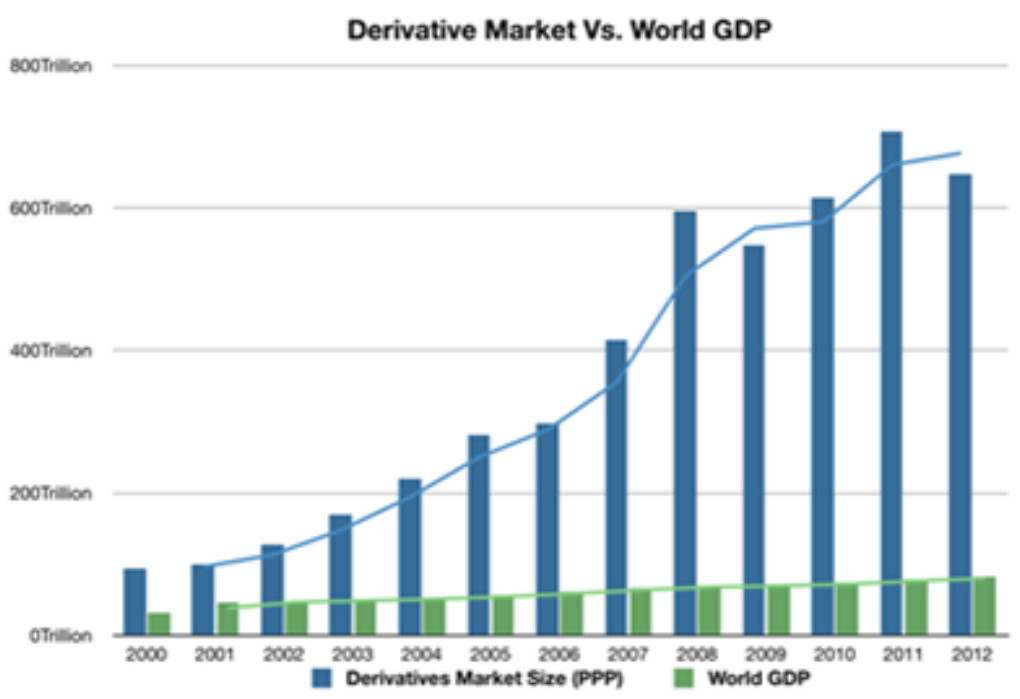

Figure 8: Derivative market Vs. World GDP.

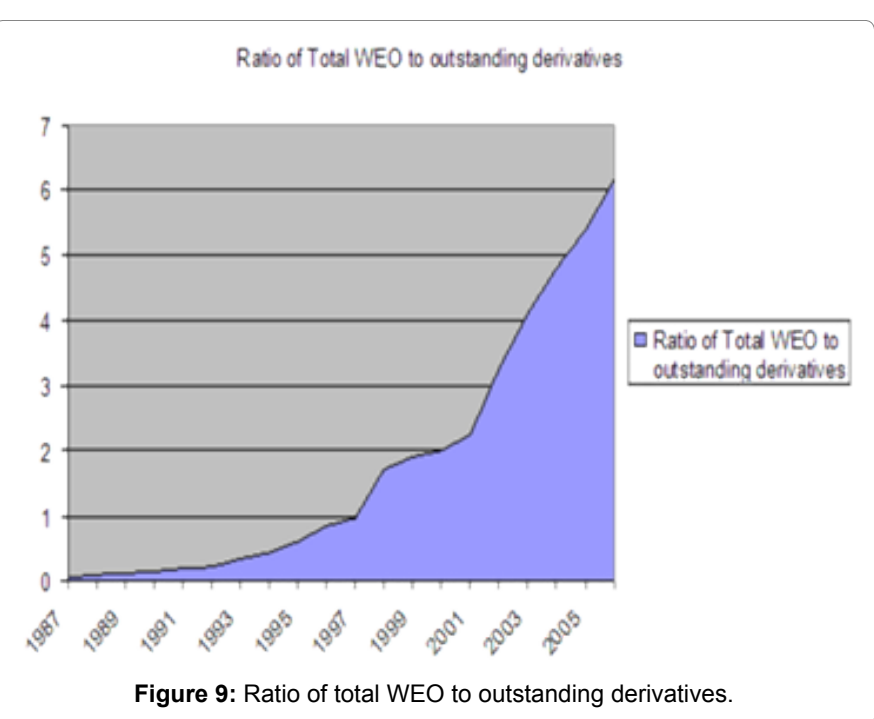

The 90 s became the theatre of experimentation inasmuch as finance as a hegemonic weapon was used as an instrument to destabilize democracy and markets. Everything seemed to turn into a game without opponents; the continuous financial bubbles prove the irrationality of markets and their subservience to higher interests. The damage to countries bordering the empire is ongoing: in South America we have Chile, Mexico (tequila bond), Argentina (tango bond), Brazil (samba bond); in the Far East we have Japan, Thailand, Malaysia, South Korea, Hong Kong and even the attack on Russia and its rouble. Precisely in this dramatic context, a cornered Russia rediscovered its ancient roots of "Mother Russia" and prepared to face the new century, looking to the future without forgetting the past and slowly returning to being an extremely difficult counterpart to the US, whose arrogance betrayed them and now leading them to a sort of sociocultural Armageddon that they will only be able to face if they are willing to question themselves.

At the end of the decade, when the financial crisis of countries bordering the empire clearly brought to light the errors of finance, Greenspan deregulated the derivatives market and eradicated the "Glass Steagall Act" that promoted by Roosevelt and Keynes in 1933 had 
separated the investment bank market from that of traditional banks. The chaos extended to $\mathrm{B} \& \mathrm{Bs}$ and the mass of uncontrolled derivatives grew to infinity as the following graphs show (Figure 8).

Bernanke then flooded the liquidity market, creating the subprime super-bubble that burst in 2008 and continues to this day because the cultural model is always only that of finance. Both Bernanke and Yellen sustained the liquidity strategy to support finance without manufacturing that was largely delocalized, but the absence of manufacturing produces only a monetary mass without GDP growth, as the following graphs show (Figure 9 and 10).

\section{Creating Shareholder Value}

The exasperated quest to create shareholder value led to the shortterm or even very short-term logic typical of a finance culture that never raises the issue of the social consequences of its actions, which in this sense can be considered inherently "amoral". The multinationals in the race to reduce costs by delocalizing destroyed manufacturing labour and its contribution to GDP, by then inadequate and insufficient to create the wealth necessary to revive the country, but the delocalization of labour also relocated taxes that went from $8 \%$ as an incidence of GDP 20 years ago to $0.7 \%$ today and totally inadequate to support welfare and reduce the explosive conflicts that are pushing the US to a point of no return, as the following graphs show (Figures 11-14):

Consequently, the financial deregulation that started in the late $90 \mathrm{~s}$ following the Nobel Prizes transformed the financial system, which welcomed businesses and consumers in a casino game where bets are not covered and where the dealer seems to regulate the apparent rationality of the roulette.

The US paid for this financial monoculture with a seemingly unbridgeable debit position and GDP that cannot grow (Figures 15 and 16).

After the collapse of Lehman Brothers in 2009, Queen Elizabeth asked the London School of Economics why they had not been able to

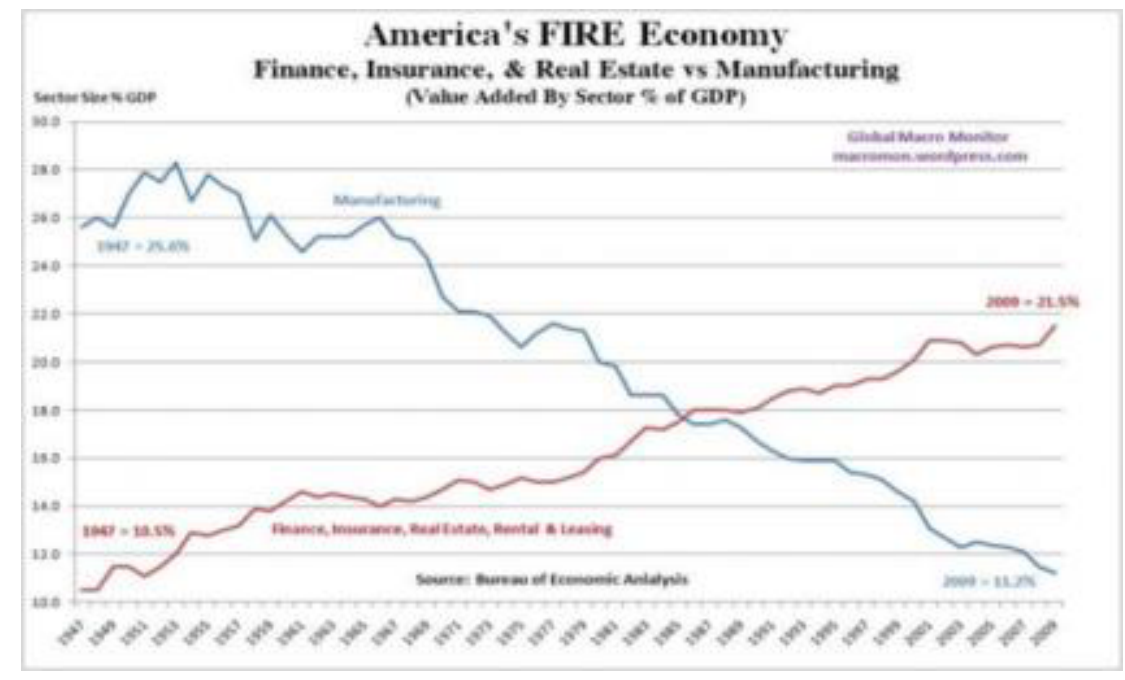

Figure 10: Finance, Insurance \& Real estate vs. Manufacturing.

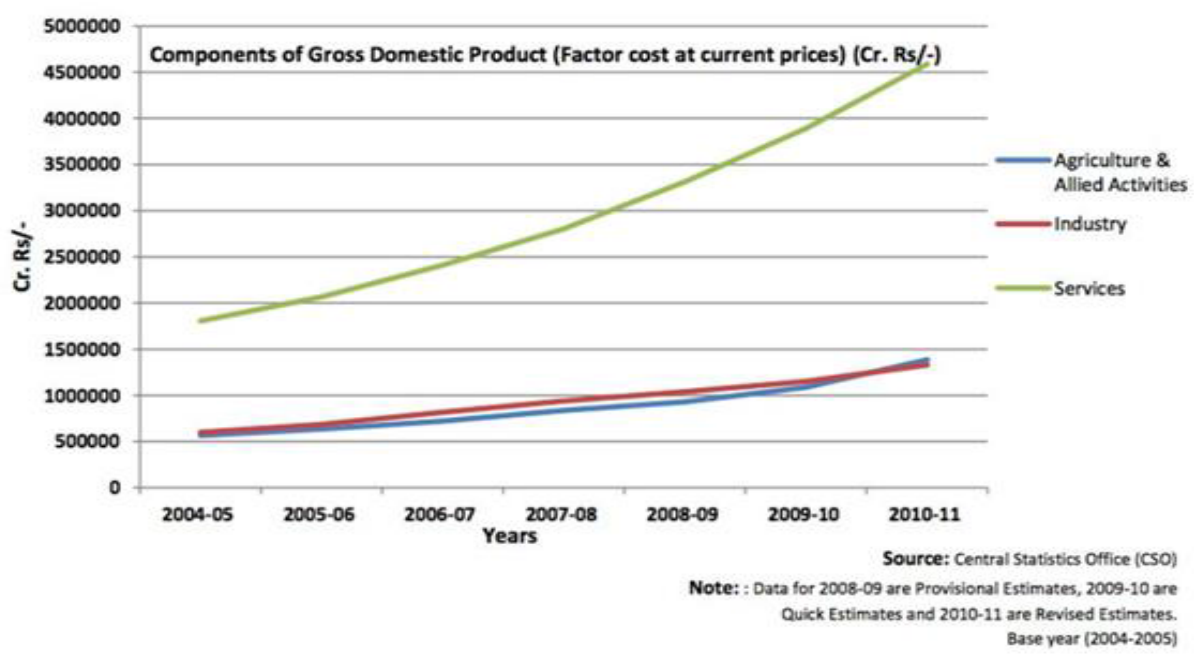

Figure 11: Components of Gross Domestic Product. 


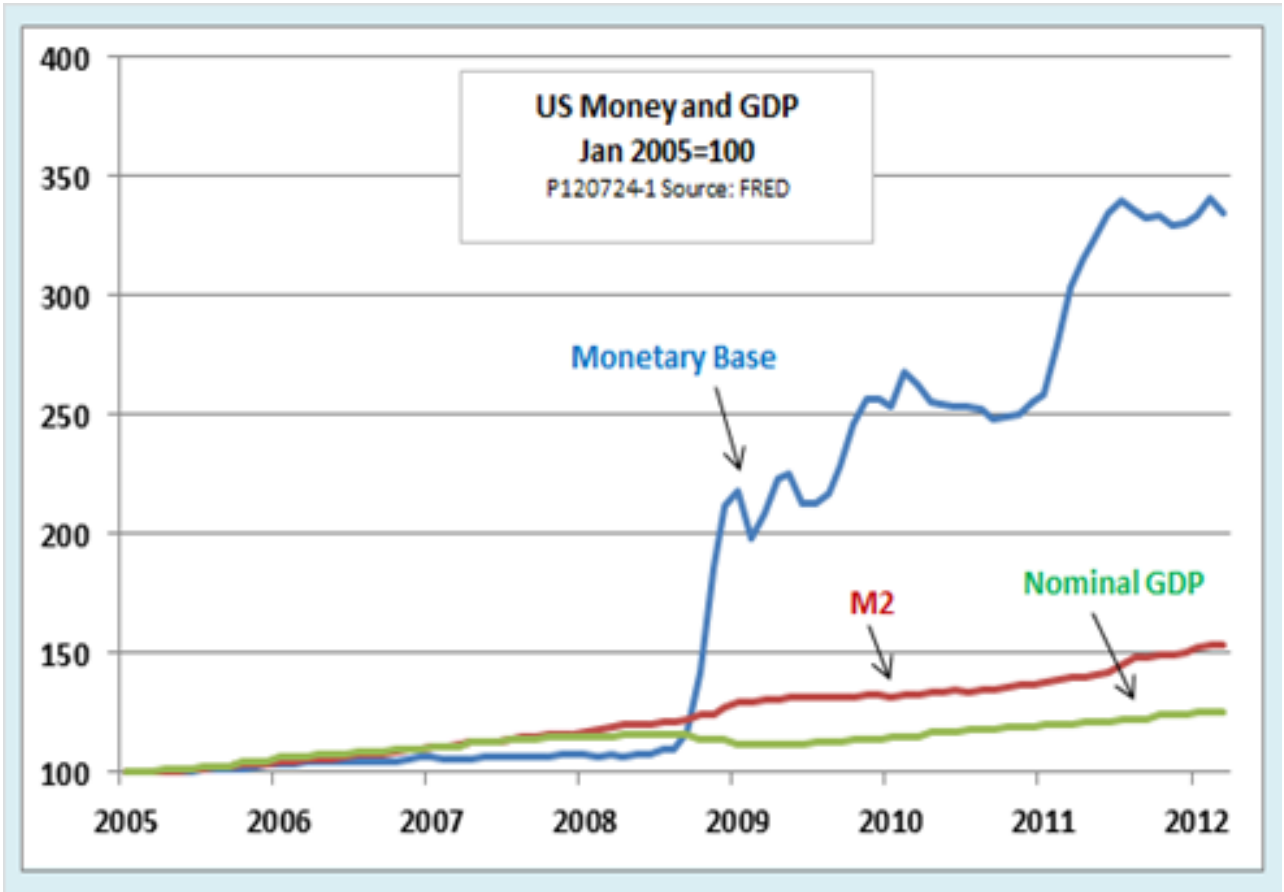

Figure 12: US Money and GDP.

\section{Now, watch out for protectionism in developed markets}

Value added as \% of GDP by industries in the US

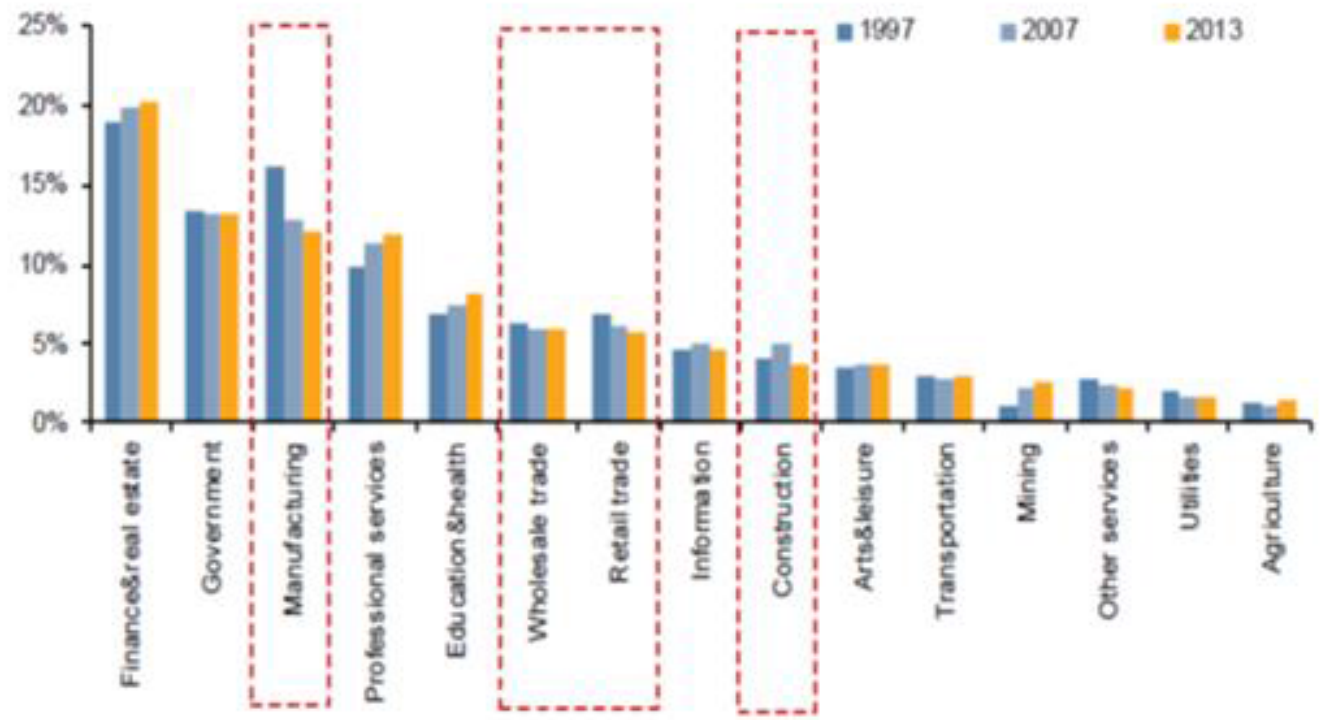

Figure 13: Protectionism in developed markets.

foresee the disaster. The School responded with two letters, a formal one ${ }^{1}$ stating something and nothing, as they say, shooting fish in a barrel, the second instead indicating exactly the reasons that F. von Hayelk had declared on the occasion of the Nobel Prize in 1974 with his lecture entitled "The Pretence of Knowledge" stating, "It seems to me that this

'http://www.feed-charity.org/user/image/besley-hennessy2009a.pdf failure of the economists to guide policy more successfully is closely connected with their propensity to imitate as closely as possible the procedures of the brilliantly successful physical sciences - an attempt which in our field may lead to outright error [...]. This brings me to the crucial issue. Unlike the position that exists in the physical sciences, in economics and other disciplines that deal with essentially complex 
phenomena, the aspects of the events to be accounted for about which we can get quantitative data are necessarily limited and may not include the important ones".

Similarly, the letter to the Queen in $2009^{2}$ recalled the same basic theme that seems to only be continually ignored:

2 http://www.thefreelibrary.com/
"We agree with many of the points made by Professors Besley and Hennessy, principally those summarized in the next paragraph, but we regard their overall analysis as inadequate because it fails to acknowledge any deficiency in the training or culture of economists themselves. Their letter rightly mentions that 'some of the best mathematical minds' were involved in risk management but 'they frequently lost sight of the bigger picture. Many believed that risks had been safely dispersed and 'virtually removed' through 'an array of novel financial instruments ...

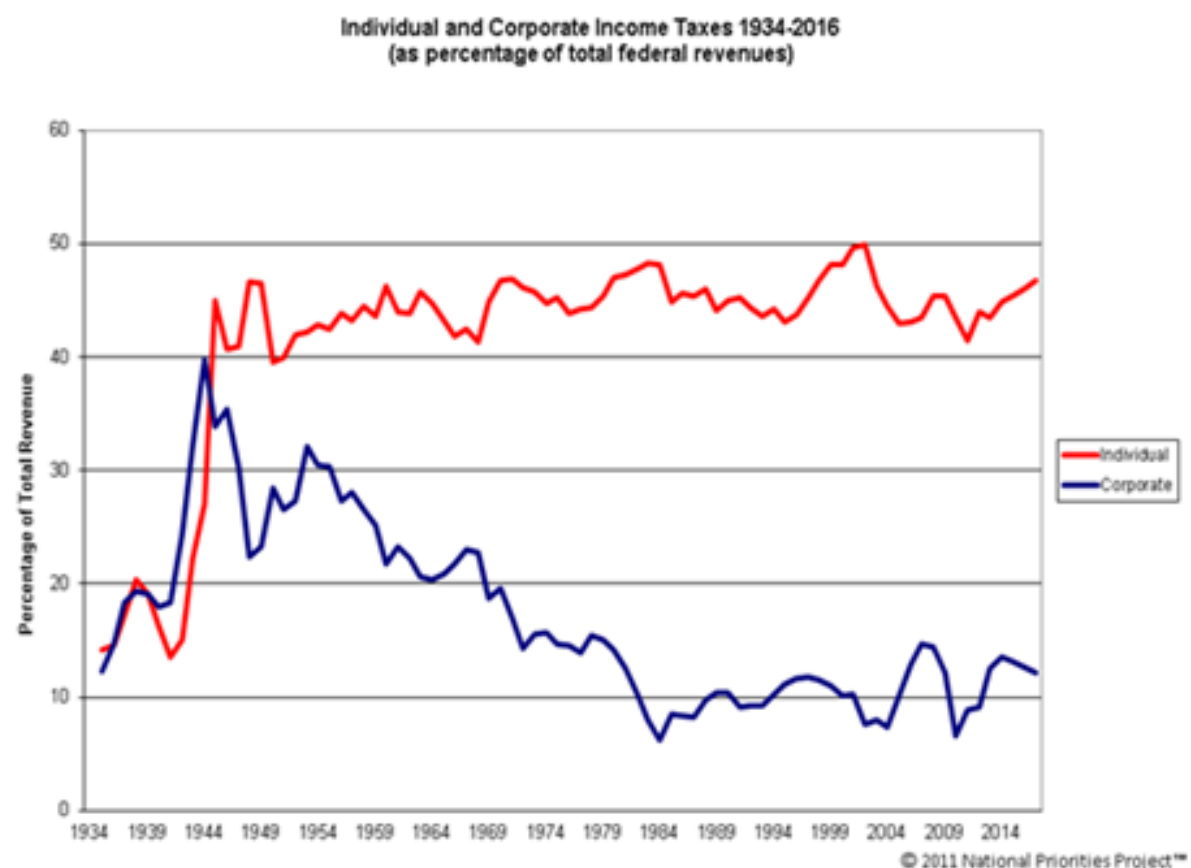

Figure 14: Individual and corporate income taxes.

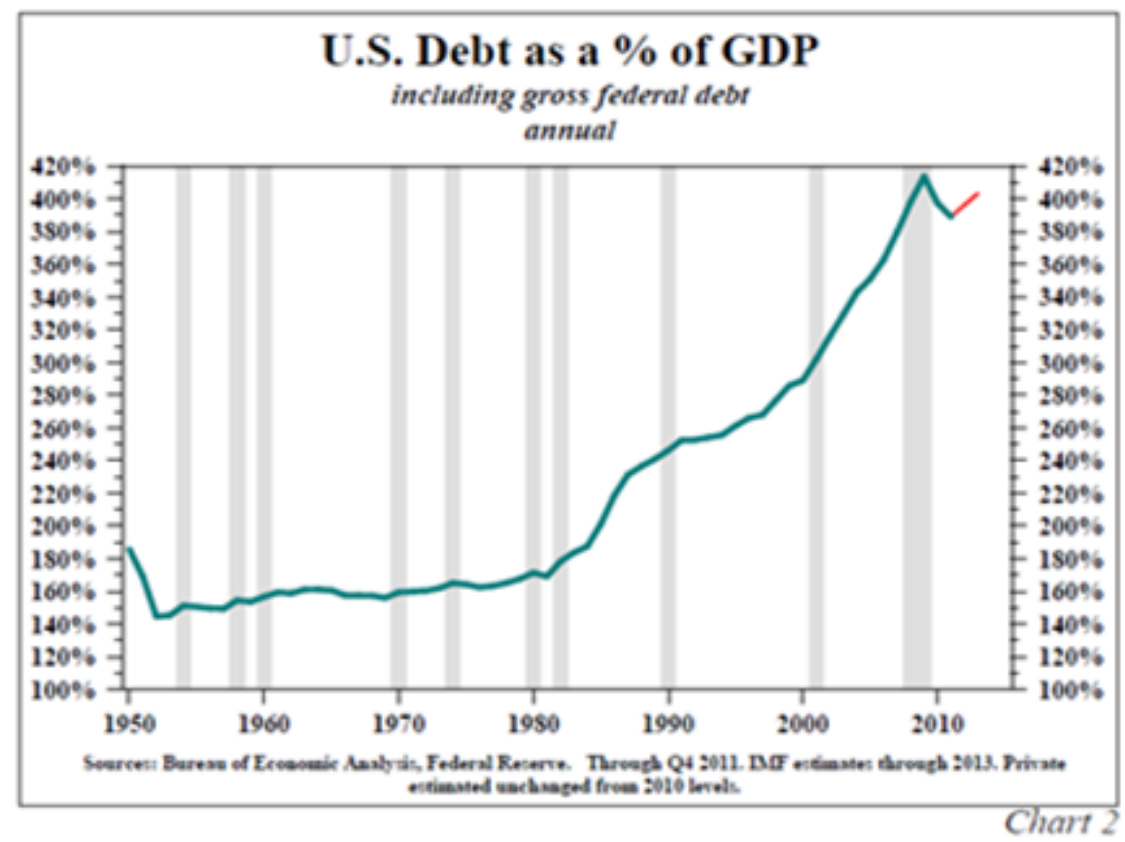

Figure 15: Annual gross federal debt. 


\section{Corrected Real GDP \\ Nominal GDP Deflated by Implicit Price Deflator Adjusted for Understatement of Annual Inflation To 1q2014, Seasonally-Adjusted (ShadowStats.com, BEA)}

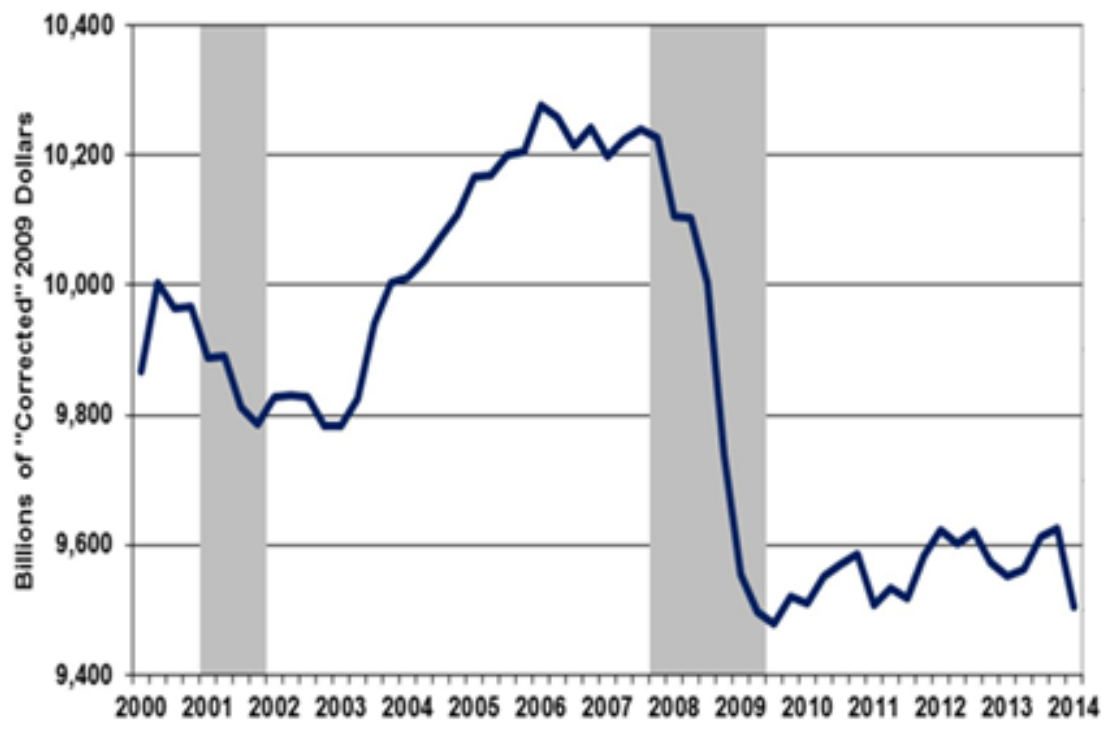

Figure 16: Corrected real GDP.

It is difficult to recall a greater example of wishful thinking combined with hubris ... and politicians of all types were charmed by the market.' In summary, they conclude, 'the failure to foresee the timing, extent and severity of the crisis and to head it off, while it had many causes, was principally a failure of the collective imagination of many bright people, both in this country and internationally, to understand the risks to the system as a whole.' In addition to the factors mentioned in their letter, we suggest that part of this responsibility lies at the door of leading and influential economists in the United Kingdom and elsewhere. Some leading economists - including Nobel Laureates Ronald Coase, Milton Friedman and Wassily Leontief - have complained that in recent years economics has turned virtually into a branch of applied mathematics, and has been become detached from real-world institutions and events. (We can document these and other complaints fully on request.) In 1988 the American Economic Association set up a Commission on the state of graduate education in economics in the US. In a crushing indictment published in the Journal of Economic Literature in 1991, the Commission expressed its fear that 'graduate programs 2 may be turning out a generation with too many idiot savants skilled in technique but innocent of real economic issues.' Far too little has since been done to rectify this problem. Consequently a preoccupation with a narrow range of formal techniques is now prevalent in most leading departments of economics throughout the world, and notably in the United Kingdom. The letter by Professors Besley and Hennessy does not consider how the preference for mathematical technique over real-world substance... For example, it does not consider the typical omission of psychology, philosophy or economic history from the current education of economists in prestigious institutions. It mentions neither the highly questionable belief in universal 'rationality' nor the 'efficient market hypothesis' - both widely promoted by mainstream economists. It also fails to consider how economists have also been 'charmed by the market' and how simplistic and reckless market solutions have been widely and vigorously promoted by many economists. What has been scarce is a professional wisdom informed by a rich knowledge of psychology, institutional structures and historical precedents. This insufficiency has been apparent among those economists giving advice to governments, banks, businesses and policy institutes. Non-quantified warnings about the potential instability of the global financial system should have been given much more attention. We believe that the narrow training of economists - which concentrates on mathematical techniques and the building of empirically uncontrolled formal models - has been a major reason for this failure in our profession. This defect is enhanced by the pursuit of mathematical technique for its own sake in many leading academic journals and departments of economics. There is a species of judgment, attainable through immersion in a literature or a history, that cannot be adequately expressed in formal mathematical models. It's an essential part of a serious education in economics, but has been stripped out of most leading graduate programmes in economics in the world, including in the leading economics departments in the United Kingdom. Models and techniques are important. But given the complexity of the global economy, what is needed is a broader range of models and techniques governed by a far greater respect for substance, and much more attention to historical, institutional, psychological and other highly relevant factors".

"The difficulties we are now facing have been caused by men, not by natural and unexpected events. Men who in many cases graduated from top universities. But what moral and ethical values are taught in these (ex) leading seats of learning? Should we not ask ourselves what responsibilities the 'experts' have who taught those who have now got us into this mess? Unfortunately, and this is the real drama, we will find them still there pontificating on a new course of history. Probably getting ready to endorse the new 'Corporate Social Reasonability' product and then write a best-seller that will last, as always, just the space of a morning, but without promoting a true cultural change. Their moral and social responsibilities are just like water off a duck's 
back to them. Words like honour, shame, ethics, solidarity, which once had a profound impact on people's consciences, seem now to always fall on deaf ears" (È tutta un'altra storia: Ritornare all'uomo e all'economia reale, Egea, Milan, 2013).

\section{Conclusion}

It is therefore quite clear that the socio-cultural model that engendered the crisis is not inherently able to resolve because its contents are asymmetric to the search for solutions. One could affirm that those who with their culture and their interests caused it have neither the culture nor the interest to solve it, yet every single day we hear their forecasts, their cures that inevitably kill the system. This cultural model must be changed both in terms of the men and the solutions, technically it could be said that the system needs to be "restored" and the responsibilities cannot be without scientific and human, moral and social judgments. The responsibility of exercising finance without moral, scientific and democratic limits has assumed a role that has led society against the fundamental human rights on which a society can grow in respect of the person. This power has been exercised with a clear determination to create a global hegemonic design that today is facing increasing obstacles in its realization from the country - the US where this power has bled the middle class and led to social conflicts as seen by the trend of unpredictable presidential elections. In this sense, the actions over time seem to manifest a precise correlation of causes and effects, connoting this as a wilful crisis to all effects, and we must start asking ourselves some questions.

Are those in charge of governing public affairs aware of the responsibilities assigned them? Is this responsibility of accounting to society (the principle of accountability) reflected in the performance of their duties or is it totally ignored? Do those who make vital decisions for the survival of man as a person have the necessary knowledge to carry out their activities and the humility to understand the difficulties that impose the duty to be morally irreprehensible? Are our youngsters educated in this logic or abandoned to the nothingness of everyday life where there seem to be no behaviours worth imitating?

Romano Guardini variously posed such questions in his splendid work "Power and Responsibility. A Course of Action for the New Age" published in 1961, which are still relevant today, demonstrating that profound thought, not glancing at waves, never belies those who can read history and the long years that constitute it. "The greater a man's power, the stronger the temptation to take the shortcut of force" (as we see every day - editor's note). "The temptation to nullify the individual and his freedom, to ignore both his creative originality and his personal truth; to achieve the desired end simply by force, dismissing what cannot be forced as not worthy of consideration - in other words, the temptation to erect a culture on rational and technical foundations alone. To this end, man himself must be considered something "marketable" ("the labour market") something that can be "managed" - i.e., "laid off or on," "conditioned" from the start to certain ends. Even spiritually man is malleable, once dialectics and mass-suggestion, propaganda and Weltanschauung or historical perspective, even legal testimony are undertaken not with respect for truth, but to support predetermined ends" as Guardini [1].

In the end, if our time is the expression of living this drama on a global level, regardless of territories, beliefs and cultures, still facing crimes against human rights, do we have the right to existence? The time has come to find some answers before the final account of history ends the adventure of man on this planet. If western society is unable to find the right way to provide answers to the many problems that are crippling it, then from a creative point of view it has nothing more to say [2].

Responsibilities are always individual, even if in different ways we have all contributed - for convenience, interest, through negligence or lack of courage - to the acceptance of these behaviours and everyone once again, each within their sphere of responsibility, should try and choose what is right and what is wrong in respect of man as a person. We are not condemned to history repeating itself, it is up to us to decide our destiny and we cannot pretend that this depends on the evolution of natural phenomena or divine will. As men of conscience, is up to us to shoulder our responsibilities, we must decide if we will allow ourselves to be a victim of our aggression and arrogance and plunge into the abyss.

\section{References}

1. Guardini R (1961) Power and responsibility: A course of action for the new age. Henry Regnery Company, Chicago.

2. Pezzani $F$ (2013) It' quite another History. Back to humanity and the rea economy. Milano, Egea. 